\title{
PERPINDAHAN PANAS HYBRID PHOTOVOLTAIC dan THERMOELEKTRIC GENERATOR DENGAN HOT MIRROR
}

\author{
Ardiansyah 1, Mustofa' ${ }^{2}$, Iskandar ${ }^{3}$, Andi Idhan ${ }^{4}$, Yuli Asmi Rahman \\ 1,2,3,4) Jurusan Teknik Mesin,Fakultas Teknik. Universitas Tadulako, \\ 5) Jurusan Teknik Elektro,Fakultas Teknik. Universitas Tadulako \\ email : Mustofa70@gmail.com
}

\begin{abstract}
Heat transfer is the transfer of energy from one area to another due to the temperature difference between these areas. Wasted heat energy can be converted into electricity using (TEG) between the hot and cold sides. If the temperature difference is more significant, the efficiency may increase along with the operating temperature of the TEG-type material. So in this study, the author will calculate the heat transfer that occurs in Photovoltaic (PV), Thermoelectric Generator (TEG), and Hot Mirrors by utilizing thermal energy light produced from Muxindo LED bulbs with 10 Watt, 15 Watt, and 20 Watt power. The results of this study indicate that by using 10,15 , and 20 Watt LED bulbs for free convection heat transfer, the power generated from each point increases because it passes through several obstacles from objects that experience a decrease in temperature to PV and TEG, with the characteristics of the displacement. The movement of molecules from the medium importance follows convection heat at every point of transfer in the intermediate substance. The most significant power generated from radiant heat transfer is about 0.1873 Watt. It occurs on the surface of the fresnel lens using a 20 Watt LED bulb with the characteristic that the radiation propagates in a straight line and does not require an intermediate medium to transfer heat from one substance to another. The most significant conduction heat transfer power, 0.2453 Watt, occurs in Fresnel Lens using a 20 Watt LED bulb with heat transfer characteristics in solid objects.
\end{abstract}

Keywords: LED bulb, Hybrid, PV, TEG, convection heat transfer.

\section{Pendahuluan}

Indonesia adalah negara yang memiliki iklim tropis dan juga memiliki potensi yang besar yang dapat dijadikan sebagai sumber energi. Energi tidak lepas dari kehidupan makhluk hidup dalam menjalankan aktivitas sehari-hari. Kebutuhan energi dari tahun ketahun semakin meningkat seiring dengan berkembangnya berbagai macam teknologi. Sumber energi yang dimanfaatkan tidak semua dapat diperbarui sehingga suatu saat sumber energi ini akan habis, seperti halnya energi fosil yang ada dibumi. Maka dari itu, pengembangan energi alternatif yang ramah lingkungan dan terbarukan perlu dilakukan agar terpenuhinya kebutuhan energi dan kelangsungan hidup tumbuhan, hewan, dan manusia. Salah satu energi yang dimanfaatkan untuk memenuhi kebutuhan manusia adalah energi matahari sebagai sumber energi dimasa depan.

Dengan melihat potensi tersebut pemanfaaan energi surya dapat dimanfaatkan menjadi energi listrik dan termal. Energi listrik dapat diperoleh salah satunya menggunakan photovoltaic. Sistem photovoltaic ini merupakan teknologi yang berfungsi untuk mengkonversi radiasi matahari dengan memanfaatkan suatu $p-n$ juction pada silikon kristal tunggal yang merupakan bahan semikonduktor. Sistem ini dapat mengumpulkan radiasi dari matahari dan mengubah radiasi matahari tersebut menjadi energi listrik. Akan tetapi photovoltaic dapat mengubah radiasi matahari menjadi energi listrik dengan efisiensi $12-18 \%$ dan lebih dari $80 \%$ energi radiasi matahari tidak diubah menjadi energi listrik tetapi diserap dan diubah menjadi energi kalor [1].

Energi kalor yang diterima secara terus menerus akan menyebabkan kenaikan temperatur kerja pada photovoltaic. Akibatnya, photovoltaic akan mengalami penurunan efisiensi elektrik. Setiap kenaikan temperatur $9-10^{0} \mathrm{C}$ pada permukaan photovoltaic akan menyebabkan penurunan 
efisiensi elektrik sebesar 5\%. Dengan demikian photovoltaic mengalami penurunan efisiensi elektrik sebesar $0,45 \%$ pada setiap kenaikan temperatur $1{ }^{\circ} \mathrm{C}[2]$.

Salah satu energi yang dapat dimanfaatkan adalah dengan memanfaatkan energi panas yang terbuang pada saluran gas buang kendaraan dan cerobong asap pada industri, dengan banyaknya energi panas yang terbuang percuma, maka energi panas yang terbuang dapat diubah menjadi energi listrik menggunakan thermoelektric generator (TEG). Modul TEG ini bekerja sesuai efek seeback. TEG dipengaruhi oleh beberapa faktor yaitu perbedaan suhu dan koefisien seeback.

Penelitian yang terkait PV dan TEG [3] adalah penelitian karakterisasi splitter spektrum dari techSpec AOI $50.0 \mathrm{~mm}$ square pada hibrid photovoltaic- thermoelektrik generator, menjelaskan bahwa radiasi spektrum cahaya tiruan (artifical lights) dari bohlam Halogen, Pijar dan Xenon setelah melewati pemisah spektrum Hot dan Cold Mirror lebih banyak energi radiasinya diarahkan ke modul Photovoltaic (PV) dibandingkan yang diterima thermoelectric generator (TEG), sehingga daya keluaran listrik PV juga lebih besar dari pada yang dibangkitkan TEG.

Dari literatur tersebut, kita dapat menyimpulkan bahwa pemanfaatan radiasi matahari dengan menggunakan sisitem photovoltaic ini merupakan teknologi yang berfungsi untuk mengkonversi radiasi matahari dengan memanfaatkan suatu $p-n$ juction pada silikon kristal tunggal yang merupakan bahan semi konduktor. Energi panas yang terbuang, dimana energi panas ini dapat diubah menjadi listrik dengan menggunakan (TEG) antara sisi panas dan dingin. Apabila semakin besar perbedaan suhunya, memungkinkan efisiensinya akan meningkat sepanjang pada suhu operasi material jenis TEG. Jadi pada penelitian ini penulis akan menghitung perpindahan panas yang terjadi pada Photovoltaic (PV), Termoelektrik Generator (TEG) dan Hot Mirror dengan dengan memanfaatkan cahaya energi thermal yang dihasilkan dari
Bohlam merk Muxindo LED dengan daya 10 Watt, 15 Watt dan 20 Watt.

\section{Metode Penelitian}

Perpindahan panas merupakan salah satu dari disiplin ilmu teknik termal yang mempelajari cara menghasilkan panas, menggunakan panas, mengubah panas, dan menukarkan panas di antara sistem fisik. Perpindahan panas didefinisikan sebagai berpindahnya energi dari suatu daerah ke daerah lainnya sebagai akibat dari perbedaan suhu antara daerah-daerah tersebut [4]. Bentuk perpindahan panas sendiri dibagi menjadi tiga macam, yaitu perpindahan panas secara konduksi, konveksi dan radiasi.

Radiasi merupakan proses perpindahan panas yang dimana melalui paket-paket energi (photon) atau gelombang elektromagnet yang dapat dibawah sampai pada jarak yang sangat jauh dan tidak memerlukan interaksi dengan medium (ini yang menyebabkan mengapa perpindahan panas radiasi sangat penting pada ruang vakum), selain itu jumlah energi yang dipancarkan sebanding dengan temperatur benda tersebut. Kedua hal yang membedakan antara peristiwa perpindahan panas konduksikonveksi dengan perpindahan panas radiasi. Perpindahan panas radiasi adalah distribusi energi berupa thermal atau panas yang terjadi melalui pancaran gelombang cahaya dari suatu zat ke zat yang lain tanpa zat perantara, besar kecilnya radiasi suatu benda tergantung pada suhu benda dan jaraknya dari sumber radiasi ke benda tersebut. Semakin tinggi suhunya semakin besar radiasi yang dikeluarkan, dan semakin jauh jaraknya semakin kecil pancaran panasnya.

Radiasi merambat dengan kecepatan cahaya, $3 \times 10^{10} \mathrm{~m} / \mathrm{s}$. Kecepatan ini sama dengan hasil perkalian panjang-gelombang dengan frekuensi radiasi [5]. Bila energi menimpa permukaan suatu bahan, maka sebagian radiasi itu dipantulkan (refleksi), sebagian diserap (absorpsi) dan sebagian lagi diteruskan (transmisi). 


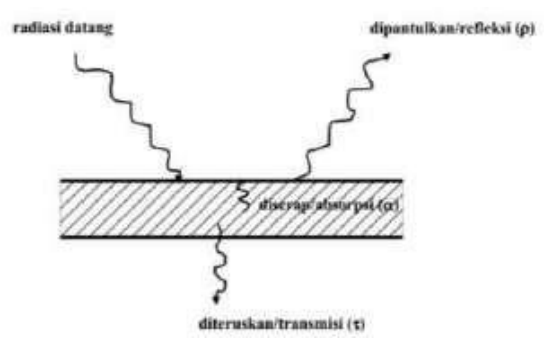

Gambar 1. Fenomena radiasi yang mengena permukaan benda [6]

Perpindahan panas radiasi ditunjukkan persamaan 1[7].

$q=\frac{\sigma\left(\mathrm{T} 1^{4}-\mathrm{T} 2^{4}\right)}{\frac{1-\varepsilon 1+1-1-\varepsilon 2}{\mathrm{~A} 1 \varepsilon 1 \mathrm{~A} 1 \mathrm{~F} 12 \mathrm{~A} 2 \epsilon 2}}$

Keterangan :

$\mathrm{q}=$ Panas yang dipancarkan (watt)

$\varepsilon_{1,2}=$ Faktor emisivitas bahan/permukaan

$\mathrm{F}_{12}=$ Faktor pandang / faktor geometri

$\mathrm{A}_{1,2}=$ Luas pancaran $\left(\mathrm{m}^{2}\right)$

$\mathrm{T}_{1}=$ Suhu mutlak pemancar panas $(\mathrm{K})$

$\mathrm{T}_{2}=$ Suhu penerima panas $(\mathrm{K})$

$\sigma=$ Konstanta stefan boltzman $\left(\mathrm{W} / \mathrm{m}^{2} \mathrm{k}^{4}\right)$

Perpindahan panas secara konduksi merupakan perpindahan panas yang melalui zat padat yang tidak ikut mengalami perpindahan panas. Dalam artian, perpindahan panas pada suatu zat itu tidak disertai dengan adanya perpindahan pada partikel-partikelnya mengikuti persamaan 2 .

$q=-K \times A \times \frac{d t}{d x}$

Keterangan :

$\mathrm{q}=$ Laju perpindahan panas (watt)

$\mathrm{U}=$ Konstanta pebanding konduktivitas thermal zat (watt $\left./ \mathrm{m} .{ }^{0} \mathrm{c}\right)$

$\mathrm{A}=$ Luas bidang perpindahan panas

$\frac{d t}{d x}=$ Gradien suhu pada arah aliran kalor $\left({ }^{0} \mathrm{c}\right)$
Perpindahan panas konveksi bebas atau konveksi alamiah terjadi karena fluida yang karena proses pemanasan berubah densitasnya (Kerapatannya), dan bergerak naik sesuai persamaan 3 .

$$
\mathrm{q}=\mathrm{h} \quad \mathrm{x} \quad \mathrm{A} \quad \mathrm{x} \quad\left(\mathrm{T}_{\mathrm{s}}-\mathrm{T}_{\infty}\right)
$$

3) Keterangan :

$\mathrm{Q}=$ perpindahan panas (watt)

$\mathrm{h}=$ Koefisien perpindahan panas konveksi ratarata pada permukaan $\left(\mathrm{watt} / \mathrm{m} .{ }^{0} \mathrm{c}\right)$

$\mathrm{A}=$ Luas bidang perpindahan panas

\section{Hasil dan Pembahasan}

\subsection{Hasil dan Pembahasan}

Pengujian ini menghasilkan data temperatur di setaiap titik yang sudah di tentukan yaitu titik $1-10$. Perpindahan panas konveksi bebas terjadi pada beberapa titik pada titik A antara Bohlam dengan Lensa Fresnel, titik B antara lensa fresnel dengan Hot Mirror, titik $\mathrm{C}$ antara Hot Mirror dengan TEG, titik D antara Hot Mirror dengan PV dengan menggunakan Bohlam KED 10,15 dan 20 Watt.

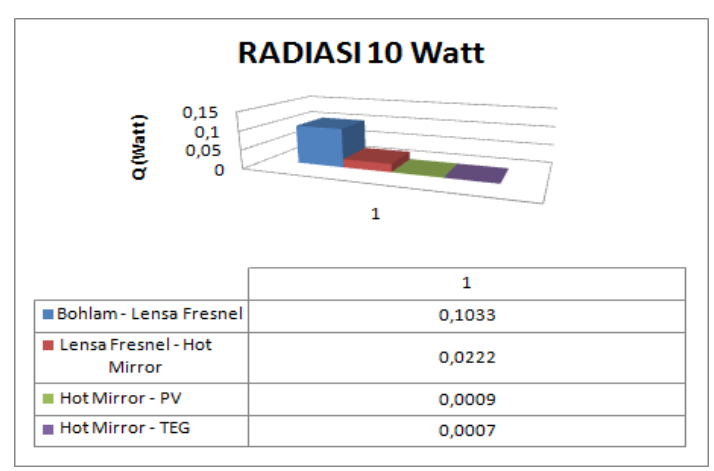

Gambar 1 Konveksi bebas dengan meggunakan Bohlam Led 10 Watt

Pada gambar 1 konveksi bebas dapat diliat perbedaan daya pada setiap titik. Titik A Bohlam - Lensa Fresnel, titik B Lensa Fresnel - Hot Mirror, titik C Hot Mirror PV, titik D Hot Mirror - TEG, dimana daya pada tititik A bohlam - lensa fresnel lebih tinggi yaitu 0,0411 Watt dibandingkan 
dengan titik $\mathrm{B}, \mathrm{C}$ dan $\mathrm{D}$, daya yang dihasilkan pada titik $\mathrm{B}$ dan $\mathrm{C}$ mengalami penurunan daya, ketika memasuki titik $\mathrm{D}$ kembali mengalami penurunan daya sebesar 0,0009 Watt.

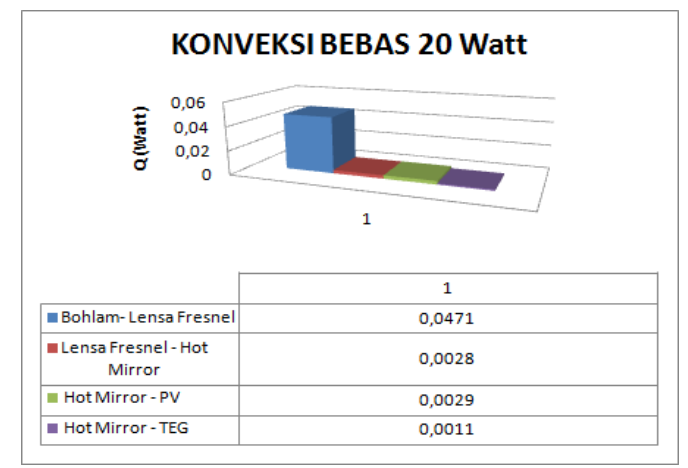

Gambar 2 Konveksi bebas dengan meggunakan Bohlam Led 20 Watt

Pada gambar 2 dapat diliat bahwa daya yang dihasilkan oleh setiap titik dengan menggunakan bohlam 15 Watt lebih tinggi dibandingkan pada bohlam 10 Watt. Titik A Bohlam - Lensa Fresnel, titik B Lensa Fresnel - Hot Mirror, titik C Hot Mirror PV, titik D Hot Mirror - TEG, dimana daya pada tititik A Bohlam - Lensa Fresnel lebih tinggi yaitu 0,0442 Watt dibandingkan dengan titik $\mathrm{B}, \mathrm{C}$ dan $\mathrm{D}$, daya yang dihasilkan pada titik $\mathrm{C}$ dan $\mathrm{D}$ mengalami penurunan daya sampai pada titik D sebesar 0,0010 Watt.

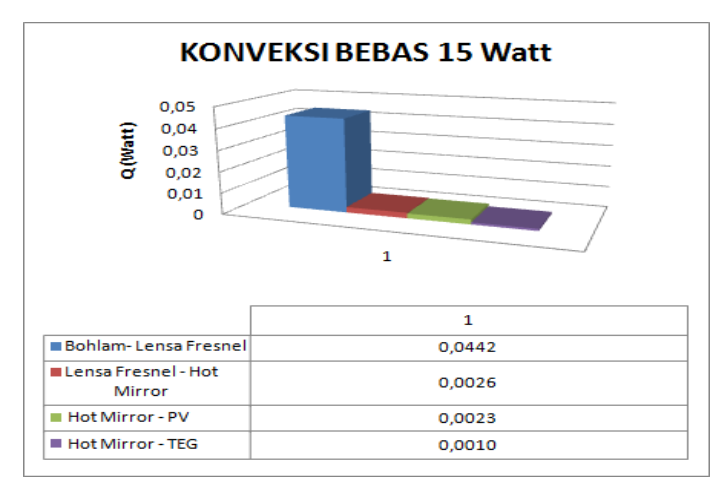

Gambar 3 Konveksi bebas dengan meggunakan Bohlam Led 15 Watt

Pada gambar 3 dapat diliat bahwa daya yang dihasilkan oleh setiap titik dengan menggunakan bohlam 20 Watt lebih tinggi dibandingkan pada bohlam 10 dan 15 Watt. Titik A Bohlam - Lensa Fresnel, titik B Lensa Fresnel - Hot Mirror, titik C Hot Mirror PV, titik D Hot Mirror - TEG, dimana daya pada tititik A Bohlam - Lensa Fresnel lebih tinggi yaitu 0,0471 Watt dibandingkan dengan titik B, C dan D, hal ini dikarenakan dengan menggunakan bohlam 20 Watt temperatur setiap permukaan benda mengalami kenaikan daya yang dihasilkan pada titik B, C dan D mengalami penurunan daya sampai pada titik D sebesar 0,0011 Watt. Hal ini disebakan karena beberapa hal yaitu perbedaan tempeatur pada permukaan (Lensa fresnel, Hot Mirror, TEG dan PV), Luas permukaan benda Lensa fresnel, Hot Mirror, TEG dan PV), Geometri dari setiap benda (Lensa fresnel, Hot Mirror, TEG dan PV) dan temperatur lingkungan.

Dari 3 grafik perpindahan panas konveksi bebas diatas menunjukkan bahwa pengaruh perbedaan temperatur setiap titik, temperatur lingkungan, luas permukaan benda, geometri dari benda akan menghasilkan daya (watt) yang berbeda pula.

Pada gambar 4 dapat dilihat bahwa perbedaan daya pada dari benda, dimana daya radisi terbesar pada Lensa Fresnel yaitu 0,1033 Watt dengan temperatur permukaan pemancar 45,1 ${ }^{\circ} \mathrm{C}$ dan Temperatur permukaan lensa fresnel sebesar $31,8^{\circ} \mathrm{C}$,

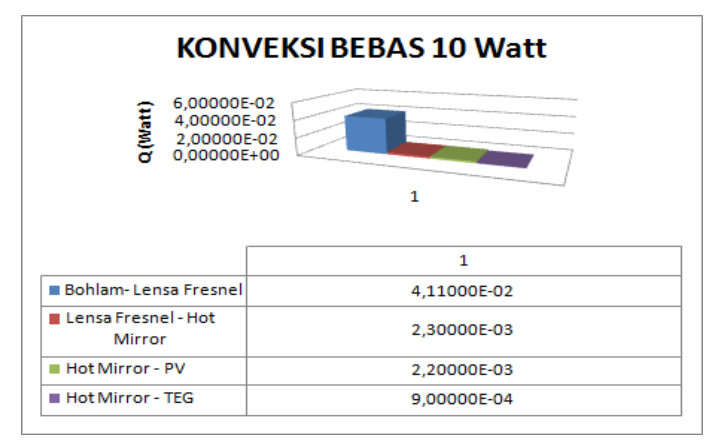

Gambar 4 Radiasi dengan meggunakan Bohlam Led 10 Watt

Setelah melewati lensa frenel terjadi penurunan daya pada Hot Mirror, PV sampai pada TEG sebesar 0,0007 Watt. Hal ini disebabkan karena tejadinya penurunan temperatur pada permukaan TEG sebesar $30,66{ }^{\circ} \mathrm{C}$ oleh karena itu daya pada PV 
kembali mengalami penurunan. Untuk daya terendah yaitu pada TEG sebesar 0,0007 Watt disebabkan kareana penurunan temperatur pada sisi panas TEG sebesar $30,66{ }^{\circ} \mathrm{C}$ dan geometri dari TEG.

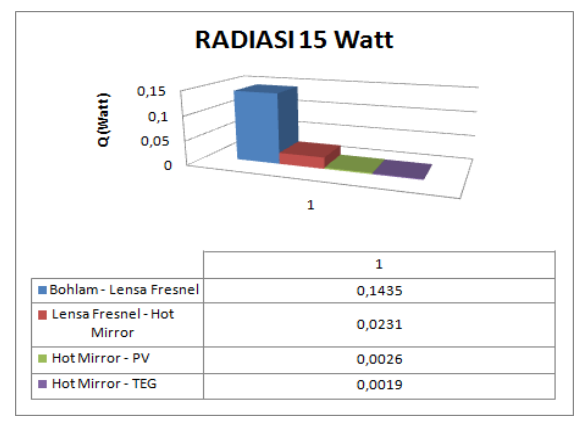

Gambar 5 Radiasi dengan meggunakan Bohlam Led 15 Watt

Pada gambar 5 dapat dilihat bahwa dengan perpindahan panas radisi daya yang dihasilkan oleh bohlam Led 15 Watt lebih besar dibandingkan dengan bohlam LED 10 Watt. Daya radisi terbesar terjadi pada Lensa Fresnel yaitu 0,1435 Watt dengan temperatur permukaan pemancar $46,03 \quad{ }^{\circ} \mathrm{C}$ dan Temperatur permukaan lensa fresnel sebesar $32,26^{\circ} \mathrm{C}$, setelah melewati lensa frenel terjadi penurunan daya pada Hot Mirror, PV dan sampai pada TEG sebesar 0,001 9 Watt. Hal ini disebabkan karena tejadinya penurunan temperatur pada permukaan Hot Mirror, PV dan TEG, oleh karena itu daya yang sampai pada TEG kembali mengalami penurunan. Untuk daya terendah yaitu pada TEG sebesar 0,0019 Watt disebabkan kareana penurunan temperatur pada sisi panas TEG sebesar 30,76 ${ }^{\circ} \mathrm{C}$ dan geometri dari benda TEG.

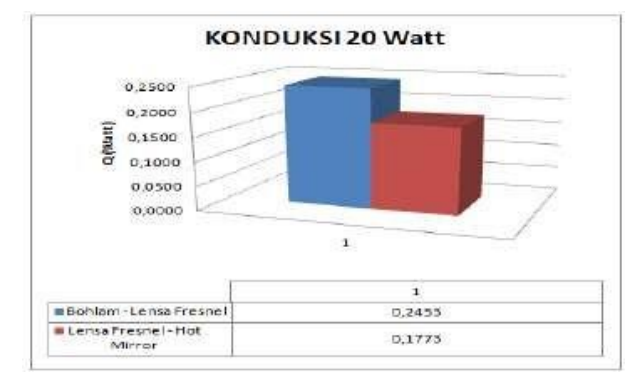

Gambar 6 Radiasi dengan meggunakan Bohlam Led 20 Watt

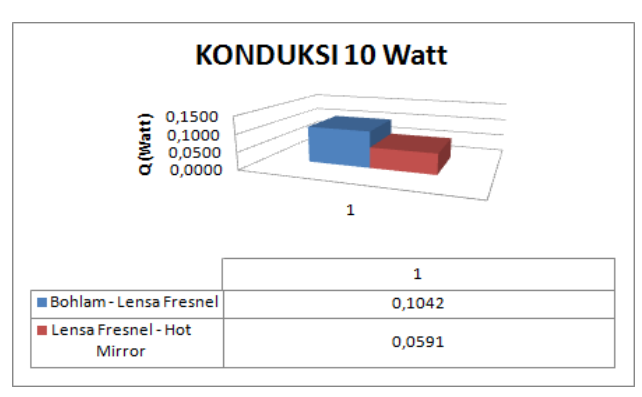

Gambar 7 Konduksi dengan meggunakan Bohlam Led 10 Watt

Pada gambar 6 dapat dilihat bahwa dengan perpindahan panas radisi daya yang dihasilkan oleh bohlam Led 20 Watt lebih kecil hanya pada titik tertentu dibandingkan dengan bohlam LED 15 Watt, hal ini dikarenakan adanya perbedaan temperatur permukaan setiap benda. Daya radisi terbesar terjadi pada Lensa Fresnel yaitu 0,1873 Watt dengan temperatur permukaan pemancar 46,06 ${ }^{\circ} \mathrm{C}$ dan Temperatur permukaan lensa fresnel sebesar $32,36{ }^{\circ} \mathrm{C}$, setelah melewati lensa frenel terjadi penurunan daya pada Hot Mirror, PV dan sampai pada TEG sebesar 0,0010 Watt. Hal ini disebabkan karena tejadinya penurunan temperatur pada permukaan Hot Mirror, PV dan TEG, oleh karena itu daya yang sampai pada TEG mengalami penurunan. Untuk daya terendah yaitu pada PV sebesar 0,0009 Watt disebabkan kareana penurunan temperatur pada sisi panas TEG sebesar 30,8 ${ }^{\circ} \mathrm{C}$ dan geometri dari benda TEG. Adapun beberapa hal yang menyebabkan menurunnya daya di setiap benda disebabkan karena perbedaan temperatur pemancar dan penerima panas, faktor emisivitas bahan, luas bahan, dan faktor pandang pada bahan.

Pada gambar 7 dapat dilihat bahwa perbedaan daya yang dihasilkan setiap benda, dimana daya dari Konduksi terbesar pada Lensa Fresnel yaitu 0,1042 Watt dengan temperatur permukaan Lensa Fresnel 31,80 ${ }^{\circ} \mathrm{C}$ dan Temperatur permukaan bawa Lensa Fresnel sebesar $31,63{ }^{\circ} \mathrm{C}$, Untuk daya terendah dari konduksi yaitu pada Hot Mirror sebesar 0,0591 Watt disebabkan karena 
turunnya temperatur pada sisi atas dan bawah Hot Mirror.

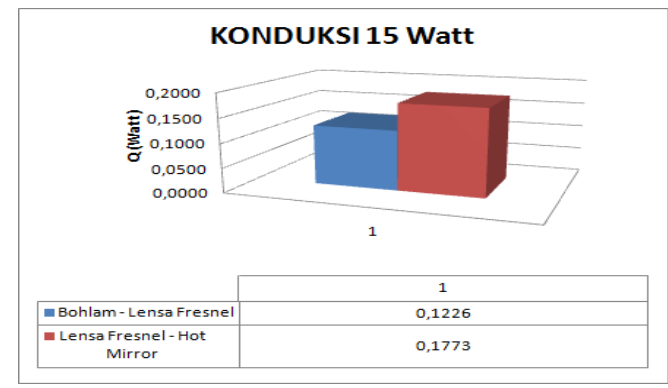

Gambar 8 Konduksi dengan meggunakan Bohlam Led 15 Watt

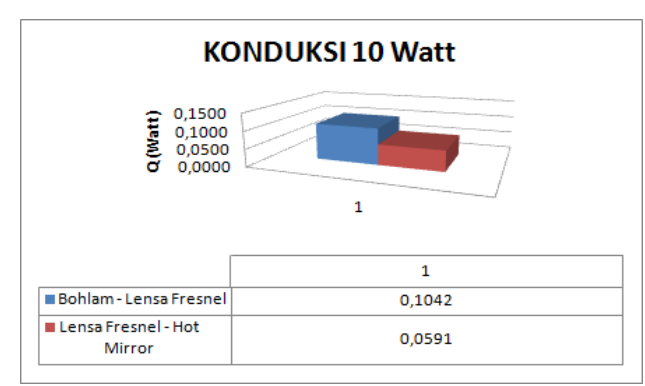

Gambar 9 Konduksi dengan meggunakan Bohlam Led 20 Watt

Pada gambar 8 dapat dilihat bahwa daya yang dihasilkan dari bohlam LED 15 Watt lebih besar dibandingkan dengan bohlam LED 10 Watt. Adapun perbedaan daya yang dihasilkan setiap benda, dimana daya dari Konduksi terbesar yaitu pada Hot Mirror sebesar 0,1773 Watt dengan temperatur permukaan Hot Mirror $31,23{ }^{\circ} \mathrm{C}$ dan Temperatur permukaan bawa Hot Mirror sebesar $30,93{ }^{\circ} \mathrm{C}$, Untuk daya terendah dari konduksi yaitu pada Lensa Fresnel sebesar 0,1226 Watt disebabkan karena turunnya temperatur pada sisi atas dan bawah Lensa Fresnel.

Pada gambar 9 dapat dilihat bahwa daya yang dihasilkan dari bohlam LED 20 Watt lebih besar dibandingkan dengan bohlam LED 15 Watt. Adapun perbedaan daya yang dihasilkan setiap benda, dimana daya dari Konduksi terbesar pada Lensa Fresnel yaitu 0,2453 Watt dengan temperatur permukaan Lensa Fresnel $32,36{ }^{\circ} \mathrm{C}$ dan Temperatur permukaan bawa Lensa Fresnel sebesar 31,96
${ }^{\circ} \mathrm{C}$, Untuk daya terendah konduksi yaitu pada Hot Mirror sebesar 0,1773 Watt disebabkan karena turunnya temperatur pada sisi atas dan bawah Hot Mirror.

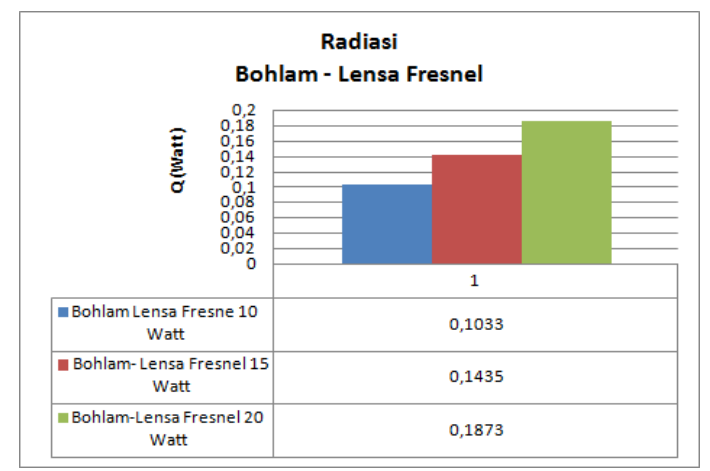

Gambar 10 Konduksi pada titik A

Adapun beberapa hal yang menyebabkan menurunnya daya di setiap benda disebabkan karena perbedaan temperatur atas dan bawah benda, Konduktivitas termal, luas bahan, dam ketebalan bahan.

Perbandingan daya di setiap titik dengan menggunakan bohlam LED Muxindo 10 Watt, 15 Watt dan 20 Watt.

1. Perpindahan Panas Konveksi Bebas pada titik A antara Bohlam - Lensa Fresnel.

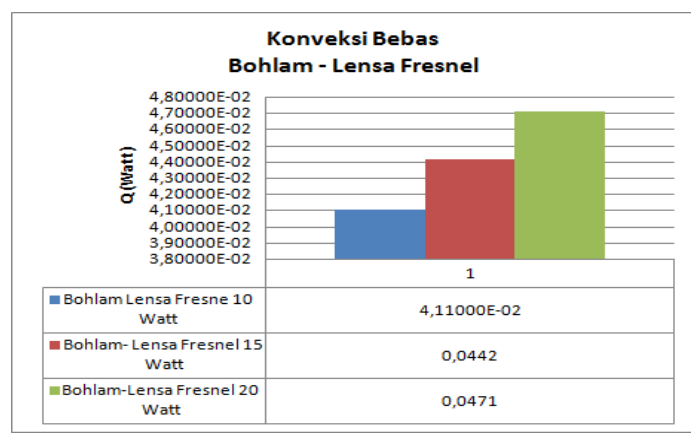

Gambar 11 Konveksi Bebas pada titik A

Pada gambar 11 dapat dilihat bahwa dayang yang dihasilkan di titik A antara Bohlam dengan Lensa Fresnel dengan menggunakan bohlam 10,15 dan 20 Watt, dimana daya tertinggi pada titik A yaitu sebesar 0,0471 Watt dibandingkan dengan bohlam 10 dan 15 Watt, hal ini dikarenakan dengan menggunakan bohlam 20 Watt temperatur permukaan benda mengalami kenaikan daya yan dihasilkan pada titik A, perbedaan temperatur pada permukaan (Lensa fresnel, Hot Mirror) luas permukaan benda, 
geometri dari setiap benda dan temperatur lingkungan. Adapun ciri perpindahan panas konveksi di titik A antara Bohlam - Lensa Fresnel dimana perpindahan panas yang zat perantaranya yang disertai dengan perpindahan molekul- molekul dari zat perantara dan disertai gerakan naik turun fluida.

Pada gambar 11 dapat dilihat bahwa dengan perpindahan panas radiasi pada titik $\mathrm{A}$ antara Bohlam - Lensa Fresnel dengan menggunakan bohlam LED 10,15 dan 20 Watt dimana daya terbesar terjadi pada Lensa Fresnel sebesar 0,1873 Watt dengan temperatur permukaan pemancar $46,03{ }^{\circ} \mathrm{C}$ dan temperatur permukaan Lensa Fresnel sebesar $32,26{ }^{\circ} \mathrm{C}$, untuk daya terkecil dengan menggunakan bohlam 10 Watt dimana daya yang dihasilkan sebesar 0,1033 Watt. Adapun beberapa hal yang menyebabkan menurunnya daya di titik A disebabkan karena perbedaan temperatur pemancar dan penerima panas, faktor emisivitas bahan, luas bahan, faktor pandang pada bahan dan daya bohlam yang digunakan. Adapun ciri perpindahan panas radiasi yaitu dimana radiasi merambat lurus dan tidak memerlukan media perantara selama memindahkan panas dari suatu zat ke zat lain.

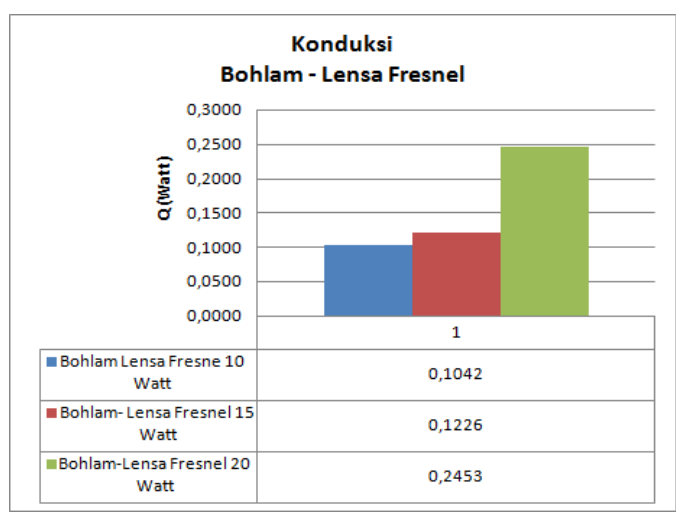

Gambar 12 Konduksi pada titik A

Pada gambar 12 dapat dilihat bahwa perpindahan panas konduksi pada Lensa Fresnel dimana daya terbesar yang dihasilkan adalah 0,2453 Watt dengan menggunakan bohlam LED 20 Watt dengan temperatur permukaan Lensa Fresnel $32,36{ }^{\circ} \mathrm{C}$ dan temperatur permukaan bawah Lensa Fresnel sebesar 31,96 ${ }^{\circ} \mathrm{C}$, untuk daya terendah konduksi yaitu sebesar 0,1042 Watt dengan menggunakan bohlam LED 10 Watt. Adapun beberapa hal yang menyebabkan menurunnya daya pada Lensa Fresnel disebabkan karena perbedaan temperatur atas dan bawah benda, konduktivitas thermal, luas bahan, ketebalan bahan dan daya bohlam LED. Adapun ciri perpindahan panas konduksi yaitu kalor pada benda padat dimana tidak disertai dengan perpindahan partikel-partikelnya.

\section{Kesimpulan}

Berdasarkan hasil eksperimen dan menganalisa perpindahan panas yang terjadi baik Konveksi bebas, Radiasi dan Konduksi, pada beberapa titik dengan menggunakan Bohlam LED Muxindo LED 10, 15 dan 20 Watt, maka dari itu dapat disimpulkan sebagai berikut :

1).Perpindahan panas secara Konveksi Bebas daya terbesar yang dihasilkan pada titik A yaitu 0,0471 Watt, titik B yaitu 0,0028 Watt, titik $\mathrm{C}$ yaitu 0,0029 Watt dengan menggunakan bohlam LED 20 Watt pada titik A - D.

2).Perpindahan panas secara Radiasi daya yang dihasilkan pada permukaan Lensa Fresnel daya terbesar yang dihasilkan 0,1873 Watt dengan bohlam LED 15 Watt, untuk permukaan Hot Mirror daya terbesar yang dihasilkan 0,0250 Watt dengan bohlam LED 20 Watt, untuk permukaan PV daya terbesar yang dihasilkan adalah 0,0026 Watt dengan bohlam LED 15 Watt, dan permukaan TEG daya terbesar dihasilkan adalah 0,0019 Watt dengan bohlam LED 15 Watt.

3).Perpindahan panas secara Konduksi daya yang dihasilkan. Pada Lensa Fresnel daya terbesar yang dihasilkan adalah sebesar 0,2453 Watt dengan menggunakan bohlam LED 20 Watt, untuk Hot Mirror daya terbesar yang dihasilkan adalah sebesar 0,1773 Watt, untuk PV dan TEG perpindahan panas secara konduksi diabaikan. 
4). Ciri dari perpindahan panas mulai dari titik A antara Bohlam dengan Lensa Fresnel, titik B antara Lensa Fresnel dengan Hot Mirror, titik $\mathrm{C}$ antara Hot Mirror dengan TEG dan titik D antara Hot Mirror dengan $\mathrm{PV}$, terdapat tiga perpindahan panas yaitu 1. Perpindahan panas Konduksi dimana perpindahan panas kalor pada benda padat tidak disertai dengan perpindahan partikel-partikelnya, 2 . Perpindahan panas Radiasi dimana terdapat radisi merambat lurus baik transmisi dan refleksi dengan sudut $45^{\circ}$. 3. Perpindahan secara Konveksi dimana adanya gerakan naik turun fluida dan perpindahan molekulmolekul dari zat perantara.

\section{Daftar Pustaka}

[1] Ekadewi 2001. Pengaruh jarak kaca ke plat terhadap panas yang diterima suatu kolektor surya plat datar “ Jurusan Teknik Mesin Universitas Kristen Petra.

[2] Kharis Burhani., 2015. "Pengembangan Media Pembelajaran Perpindahan Panas Radiasi Dengan Variasi Beda Perlakuan Permukaan Spesimen Uji.”. Teknik Mesin, Fakultas Teknik, Universitas Negeri Semarang.

[3] Vorobiev \& Vorobiev., 2016. "Hibrid PV-TEG Dan Konsentrator Lensa Fresnel Dengan Fluida Pendingin Dengan Simulasi Dan Eksperimen Dalam Bentuk Prototipe"

[4] Idawati Supu,dkk., 2016 . "Pengaruh Suhu Terhadap Perpindahan Panas Pada Material Yang Berbeda", Studi Fisika, Fakultas Sains, Universitas Coktoaminoto Palopo. Incropera \& Dewitt. Spektrum Elektrimagnetik, 1990 : 698 .

[5] Mustofa, dkk., 2018. "A New Hybrid of Photovoltaic-thermoelectric Generator with Hot Mirror as Spectrum Splitter. Department of Mechanical Engineerin", Universitas Hasanuddin.
[6] Eko Julianto, dkk.,. 2019. "Analisis perpindahan panas pada kaca lembaran jenis Soda-Lime Glass"

[7] Wahyono,. 2019. "Pembuatan alat uji perpindahan pana secara radiasi. Program Studi Teknik konservasi Energi“, Jurusan Teknik Mesin, Politeknik Negeri Semarang.

[8] Wahyu H. Piarah, dkk 2019. Simulasi Sistem Hibrid Fotovoltaik Dan Generator Termoelektrik Dengan Beam Splitter Cold.

[9] Mustofa. 2019. "Characterization Of An Artifical Suns Light Spectrum Using Tecchspec Aoi 50.0 Mm Square Hot And Cold Mirrors For A PhotovoltaicThermoelectric Generator Hybrid." Disertasi

[10] Wahyono,. 2019. "Pembuatan alat uji perpindahan pana secara radiasi. Program Studi Teknik konservasi Energi“", Jurusan Teknik Mesin, Politeknik Negeri Semarang.

[11] Menghani, S.Et.al., 2012. Low Pressure Steam Generation By Solar Energy With Fresnel Lens" IOSR Journal Of Mechanical And Civil Engineering (IOSR-JMCE), IAAN : 2278-1684. PP: 60-63.

[12] Nurhayati, dkk.,. 2021. "Pengukuran Radiasi kalor pada beberapa Bohlam yang berbeda warna." Universitas Islam Negeri Ar- Raniry. 